\title{
Magnitude of missed opportunities for prediabetes screening among non-diabetic adults attending the family practice clinic in Western Nigeria: Implication for diabetes prevention
}

\begin{tabular}{|c|c|}
\hline $\begin{array}{l}\text { Authors: } \\
\text { Oluwaseun S. } \\
\text { Ademola O. E } \\
\text { Akinfemi J. Fat } \\
\text { Bolatito B. Fat } \\
\text { Odunola O. Oj } \\
\text { Farouq A. Olo } \\
\text { Patience A. Er } \\
\text { Oluseyi A. Afo } \\
\text { Ayomiposi A. }\end{array}$ & 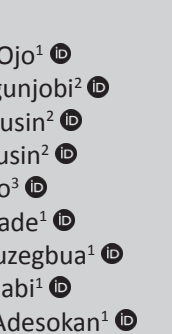 \\
\hline \multicolumn{2}{|c|}{$\begin{array}{l}\text { Affiliations: } \\
{ }^{1} \text { Department of Family } \\
\text { Medicine, Federal Medical } \\
\text { Centre, Abeokuta, Nigeria }\end{array}$} \\
\hline \multicolumn{2}{|c|}{$\begin{array}{l}{ }^{2} \text { Department of Family } \\
\text { Medicine, Federal Medical } \\
\text { Centre, Zamfara, Nigeria }\end{array}$} \\
\hline \multicolumn{2}{|c|}{$\begin{array}{l}{ }^{3} \text { Department of Nursing, } \\
\text { School of Nursing, } \\
\text { Abeokuta, Nigeria }\end{array}$} \\
\hline \multicolumn{2}{|c|}{$\begin{array}{l}\text { Corresponding author: } \\
\text { Oluwaseun Ojo, } \\
\text { ojo_teenager@yahoo.com }\end{array}$} \\
\hline \multicolumn{2}{|c|}{$\begin{array}{l}\text { Received: } 13 \text { Jan. } 2020 \\
\text { Accepted: } 25 \text { June } 2020 \\
\text { Published: } 20 \text { Aug. } 2020 \\
\text { Republished: } 22 \text { Dec. } 2020\end{array}$} \\
\hline \multicolumn{2}{|c|}{$\begin{array}{l}\text { How to cite this article: } \\
\text { Ojo OS, Egunjobi AO, } \\
\text { Fatusin AJ, et al. Magnitude } \\
\text { of missed opportunities for } \\
\text { prediabetes screening among } \\
\text { non-diabetic adults attending } \\
\text { the family practice clinic in } \\
\text { Western Nigeria: Implication } \\
\text { for diabetes prevention. } \\
\text { S Afr Fam Pract. 2020;62(1), } \\
\text { a5082. https://doi.org/ } \\
\text { 10.4102/safp.v62i1.5082 }\end{array}$} \\
\hline \multicolumn{2}{|l|}{ Read online: } \\
\hline 口解回 & $\begin{array}{l}\text { Scan this QR } \\
\text { code with your } \\
\text { smart phone or } \\
\text { mobile device } \\
\text { to read online. }\end{array}$ \\
\hline
\end{tabular}

Background: Prediabetes in primary care patients is often unrecognised, with a resultant loss of opportunity for diabetes prevention. A paucity of information about the magnitude of missed opportunities for prediabetes screening in Nigeria and other African countries exists.

Methods: A cross-sectional study was conducted amongst 417 primary care participants aged $\geq$ 18 years. A questionnaire was administered and respondents were assessed for a missed opportunity for prediabetes screening using seven risk factors identified from guidelines. The fasting blood glucose (FBG) test was performed with capillary blood using a glucometer (Accucheck Advantage, Roche Diagnostics, Mannheim, Germany). Prediabetes was defined as an FBG of $5.6 \mathrm{mmol} / \mathrm{L}-6.9 \mathrm{mmol} / \mathrm{L}$ according to the American Diabetes Association (ADA) guidelines.

Results: The incidences of missed prediabetes and diabetes diagnoses were $8.8 \%$ and $1.0 \%$, respectively. The proportion of respondents who had various risk factors that met screening guidelines but missed the opportunities for prediabetes screening was between $2.2 \%$ and $44.1 \%$. Approximately $80 \%$ of the respondents had at least one of the seven guideline-recommended risk factors but were not screened by the clinic doctors. The higher the number of risk factors in the respondents, the higher the proportion of respondents with a missed prediabetes diagnosis.

Conclusion: There were missed opportunities for prediabetes screening and consequent diabetes prevention identified in this study. The finding that high-risk patients with prediabetes in our setting often missed the opportunity to be detected through screening suggests that primary care physicians in our setting need to improve on the practice of prediabetes screening.

Keywords: prediabetes; diabetes; missed opportunity; missed diagnosis; primary care; primary care physicians; family practice clinic.

\section{Introduction}

Prediabetes is a high-risk state for diabetes, characterised by blood glucose levels that are higher than normal but not in the diabetic range. There is an increasing prevalence of prediabetes worldwide. ${ }^{1,2,3,4,5,6,7,8,9}$ Recent data have shown that in developed countries, more than one-third of adults have prediabetes. ${ }^{1,2}$ A high prevalence of prediabetes has already been established in the countries of the Middle East and Africa, where the prevalence has been described as 'alarming' or 'dramatic'. ${ }^{3}$ In Nigeria, the prevalence of prediabetes that depends on the criteria and study population varies between and across studies. ${ }^{4,5,6,7,8}$ The prevalence of prediabetes in various Nigerian studies has been reported to be between $1.1 \%$ and $22.3 \%{ }^{4,5,6,7,8}$

The diagnostic criteria of prediabetes are fairly uniform across various international guidelines, ${ }^{9,10,11,12,13,14}$ except for the American Diabetes Association (ADA) lower cut-off of $5.6 \mathrm{mmol} / \mathrm{L}$ as opposed to $6 \mathrm{mmol} / \mathrm{L}$ for impaired fasting glucose (IFG). ${ }^{10}$ Prediabetes is a long prodromal stage that people with type- 2 diabetes mellitus (DM) go through. It is often asymptomatic and, without treatment, one-third to half of people with prediabetes will progress to type-2 diabetes over 6 years. ${ }^{15}$ Prediabetes is also a predictor of cardiovascular disease (CVD).${ }^{9,10}$ If the condition is left to progress to diabetes, the risk of CVD increases three- to fourfold. ${ }^{10}$

Copyright: (C) 2020. The Authors. Licensee: AOSIS. This work is licensed under the Creative Commons Attribution License.

Correction note: In the original article published, the incorrect abstract reflects and the third author's first name was misspelt as 'Adefemi'. The abstract has been corrected in the 'Abstract' section and the author's first name rectified to read as 'Akinfemi'. These corrections do not alter the study's findings or overall interpretation of the results. The publisher apologises for any inconvenience caused. 
Scientific evidence suggests that people with prediabetes can delay or reverse the progression to type-2 DM. ${ }^{15}$ The Diabetes Prevention Program (DPP) demonstrated that in overweight adults with prediabetes, lifestyle modification including modest weight loss, dietary change and increased physical activity reduced the risk of developing type-2 DM by $58 \%$, whilst drug intervention with metformin reduced the risk by $31 \%{ }^{1}$ Given the enormous health burden posed by prediabetes, especially in sub-Saharan Africa, and its favourable reversibility potential if detected, intervention in the 'prediabetes' stage of the disease to prevent progression to diabetes and its complications may be a sensible approach to reduce the already huge burden of DM.

The majority of people living with prediabetes and DM seek care in primary healthcare facilities ${ }^{16,17,18}$ and, by extension, the General Outpatient Department (GOPD) of teaching hospitals in Nigeria because of the weak primary healthcare system. Primary care offers the best opportunity to identify people at high risk of prediabetes. ${ }^{18}$ Screening for prediabetes meets most of the five criteria that define optimal conditions for screening for any disorder. ${ }^{19}$ However, there is strong evidence that screening for prediabetes is an underutilised resource in primary care. Many primary care physicians also lack the knowledge of the risk factors, diagnostic criteria, management and prevention of prediabetes. ${ }^{20,21,22}$ Based on the aforementioned factors, it is sensible to say that many patients with prediabetes may be missed in primary care. The situation will be even worse in a low resource setting like Nigeria, where there are limited consultation times because of the overwhelmingly heavy patient load and low doctor-to-patient ratios. ${ }^{23}$

The early identification of patients who may likely have prediabetes through risk factors for prediabetes can improve screening and reduce missed diagnoses of prediabetes amongst patients attending the primary care facilities. To date, there has been no study conducted in Nigeria and Africa on the magnitude of missed opportunities for prediabetes screening in routine primary care physicians' visits. This study aimed to determine the incidence of missed prediabetes diagnoses and to describe the magnitude of missed opportunities for prediabetes screening amongst primary care patients attending the family practice clinic of a tertiary hospital in Western Nigeria using the guidelinerecommended risk factors. This may be an important step in improving the rate of prediabetes detection and diabetes prevention interventions.

\section{Operational definitions}

- Prediabetes was defined as not being diagnosed with prediabetes previously and not on treatment for diabetes but having IFG of $5.6 \mathrm{mmol} / \mathrm{L}-6.9 \mathrm{mmol} / \mathrm{L} .{ }^{10}$

- Undiagnosed diabetes was defined as diabetes not previously detected in patients having a fasting blood glucose $(\mathrm{FBG})$ of $\geq 7.0 \mathrm{mmol} / \mathrm{L.}^{10}$
- Risk factors of prediabetes are factors or conditions the presence of which will positively increase the likelihood of an existing prediabetes. In this study, seven risk factors were identified from various guidelines on prediabetes ${ }^{9,10,11,12,13,14}$ : age $\geq 45$ years, body mass index $(B M I) \geq 25 \mathrm{~kg} / \mathrm{m}^{2}$, waist circumference, hypertension, previous deliveries of big babies, gestational diabetes and family history of DM in first-degree relatives.

- Missed diagnosis was defined in this study as a nondiabetic patient who had been seen and discharged from the clinic by the doctor but was discovered to have prediabetes following an FBG test by the research team.

- A missed opportunity was defined in this study as the inability of the primary care physicians to screen a nondiabetic patient who was eligible for prediabetes screening based on any of the seven risk factors.

\section{Research methods Study design}

This was a hospital-based cross-sectional descriptive study.

\section{Study setting}

The study was carried out at the General Outpatient Clinic (GOPC) of a tertiary hospital in south-west Nigeria. Nigeria has a weak primary healthcare system. The frail state of Nigerian primary healthcare places a heavy burden on tertiary hospitals. This results in inversion of the pyramidal distribution of patients such that the majority of patients who should be cared for at primary care level are seen at the GOPC of tertiary hospitals. This makes the GOPC of a tertiary hospital in Nigeria a first contact facility for many patients.

\section{Study population}

The study population consisted of adult male and female patients aged 18 years and over attending the GOPC of the hospital. A monthly average of 1168 patients was seen at this clinic.

\section{Exclusion criteria}

The exclusion criteria for the study were the following:

- patients with previously diagnosed DM

- patient who were not previously diabetic but had been sent for a blood glucose test by the attending doctor

- patients who had had a blood glucose test done in the last year

- patients who used drugs that could affect glucose metabolism, for example, steroids, Vitamin C, B-blockers, thiazide diuretics

- pregnant women

- patients with a severe illness that would make it difficult to follow the study protocol.

Sample size: The sample size was calculated using the following formula ${ }^{24}$ : 
$n=z^{2} p q / e^{2}$

[Eqn 1]

The above formula was used in this study because the estimated population size (number of patients attending GOPD in a year) was more than 10000 .

$p=50 \%$ (because there was no previous study on the incidence of missed prediabetes diagnosis among primary care patients who had previously been seen by doctors)

$q=1-p=50 \%$. At 95\% confidence level and precision level of $5 \%, Z=1.96$ and $e=0.05$

$n=1.96^{2} \times 0.5 \times(1-0.5) / 0.05^{2}$

$n=384.16$

However, to allow for missing data, the adjusted sample size $(n 1)$ using an attrition $(d)$ of $10 \%$ was calculated using the formula:

$n 1=n /(1-d)=384.16 /(1-0.1)=384.16 / 0.9=426.8$.

This was approximated to 427

[Eqn 2]

\section{Sampling method}

A systematic random sampling technique was used to select 427 subjects attending the GOPC over a period of one month. With a monthly average of 1168 patients, the sampling interval was $(1168 / 427)=2.74$. Therefore, every third patient who had previously been seen by the clinic doctors at our GOPC and who met the selection criteria was enrolled into the study. Consent was obtained from patients in order of their arrival at the clinic. The first three patients were asked to select one from three folded ballot paper strips containing two 'No' and one 'Yes' option. Amongst the three participants, the one who selected the ballot paper containing 'yes' was selected as the first participant. After the selection of the first participant, every third consenting and eligible patient who came to the clinic was recruited. This process was repeated on subsequent days until the desired sample size was achieved.

\section{Data collection and procedure}

The usual practice at our GOPC is for the clinic nurses to do the vital signs assessment at the nursing station before patients see the doctor in the consulting room. After the patients had been completely examined by the doctors working at the GOPC, they were called into another consulting room where the principal investigator and co-investigators of this study engaged them. The exclusion criteria were ruled out through taking a brief history, a physical examination and a review of patients' case files. Consent was obtained from eligible patients.

Baseline demographic and clinical factors were obtained by the investigators through an interview using a pretested questionnaire (Appendix 1). The questionnaire consisted of four sections: socio-demographic variables, guidelinerecommended risk factors, physical examination and investigation.
The socio-demographic information included age, gender, level of education, marital status, ethnicity and religion. The guideline-recommended risk factors comprised the seven risk factors that had been identified from various guidelines for prediabetes, $, 10,11,12,13,14$ which included age $\geq 45$ years, BMI $\geq 25 \mathrm{~kg} / \mathrm{m}^{2}$, waist circumference, hypertension, previous deliveries of big babies, gestational diabetes and family history of diabetes in first-degree relatives.

Missed opportunities for prediabetes screening in this study were defined based on seven risk factors that had been identified from various guidelines on prediabetes. A missed opportunity was defined in this study as the inability of the primary care physicians to screen a non-diabetic patient who was eligible for prediabetes screening based on any of the seven risk factors mentioned above.

Blood pressure (first and fifth Korotkoff sounds) was measured twice by using a standardised mercury sphygmomanometer, 3 minutes apart consecutively on seated participants after they had rested for $5 \mathrm{~min}$. An appropriately sized cuff was placed on the right arm and pulse occlusion pressure was determined. The cuff was inflated to $20 \mathrm{mmHg}$ above that pressure. Systolic blood pressure (SBP) and diastolic blood pressure (DBP) were measured at Korotkoff sounds I and V. ${ }^{25}$ The mean of each of these two measurements was used for the estimation of SBP and DBP. The standard definition of hypertension as SBP of $\geq 140 \mathrm{mmHg}$ and/or DBP $\geq 90 \mathrm{mmHg}$ or current use of antihypertensive medicines was used..$^{26}$

Height $(\mathrm{cm})$ and weight $(\mathrm{kg})$ were measured to the nearest $0.1 \mathrm{~cm}$ and $0.1 \mathrm{~kg}$, respectively, according to the standard guideline. ${ }^{26}$ Weight measurement was taken using a weighing scale, with the participant standing still in the middle of the weighing scale's platform, without touching anything and with the body weight equally distributed on both feet. Height was measured using a stadiometer, with the participant standing straight, head in the horizontal plane (i.e. looking forward), heels together, arms to both sides, shoulders relaxed and wearing neither shoes nor head wear. Heels, buttocks, scapulae and occiput were against the vertical board of the stadiometer. The headboard of the stadiometer was then lowered onto the highest point of the head with enough pressure to compress the hair. The measurement was read visually at the same level as the headboard to avoid errors because of parallax. ${ }^{26}$ Body mass index was calculated and patients were stratified into underweight, normal, overweight and obese based on the BMI. ${ }^{27}$ Waist circumference was measured using a flexible measuring tape, with measurements taken halfway between the lower border of the ribs and iliac crest in a horizontal plane. A waist circumference greater than $88 \mathrm{~cm}$ for women and $102 \mathrm{~cm}$ for men was considered to be abnormal. ${ }^{28}$

After the blood pressure and anthropometric measurements were done, each respondent was counselled on the 
importance of undergoing a definitive test for DM. Each participant was given an investigation slip and informed to come to the GOPC in the morning of any clinic day according to their convenience within the study period for the definitive tests (FBG) using glucometer (Accu-check Advantage, Roche Diagnostics, Mannheim, Germany). To reduce loss to follow-up, the participants were reminded telephonically about their appointment for the FBG test a day prior to it.

On the appointment day for the definitive test, FBG was measured by the investigators at the GOPC. The participant's thumb fingertip was cleaned with an alcohol swab and the arm was allowed to hang down to let blood flow to the fingertip. The side of the thumb was pricked with a lancet and the drop of blood formed was sucked into the test strip. Blood glucose level was read from the glucometer screen. Respondents with an FBG of $\geq 7 \mathrm{mmol} / \mathrm{L}$ were diagnosed as having DM. ${ }^{10}$ Respondents with FBG between $5.6 \mathrm{mmol} / \mathrm{L}$ and $6.9 \mathrm{mmol} / \mathrm{L}$ were diagnosed as having prediabetes. ${ }^{10}$ Respondents with either prediabetes or DM were regarded as having dysglycaemia. Those who did not come for the FBG were considered as being a loss to follow-up. Those who had an FBG of $\geq 7 \mathrm{mmol} / \mathrm{L}$ (diabetes) were sent to the laboratory for a repeat test, which eventually confirmed DM. Newly diagnosed diabetic and prediabetic respondents were properly counselled regarding diets, exercise and

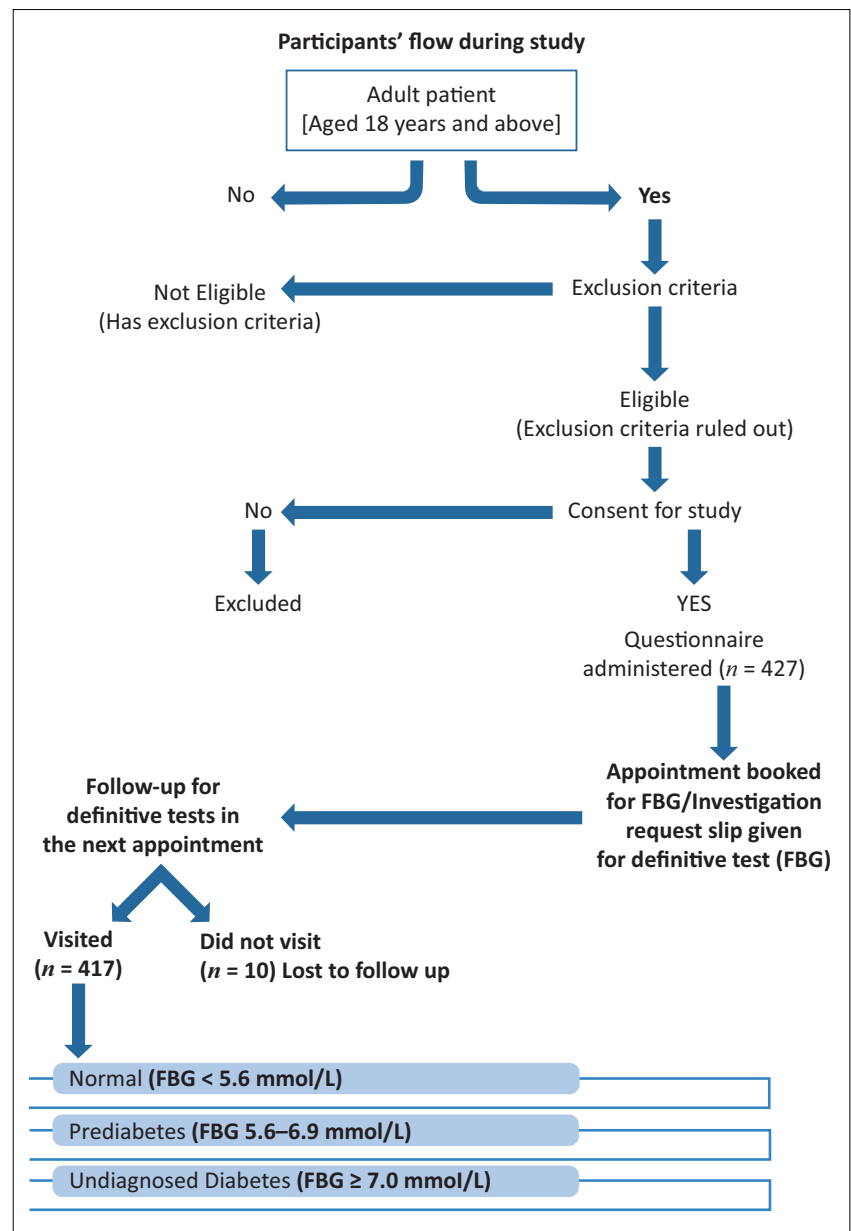

FIGURE 1: Participants' flow during the study. adherence to medications, for those who needed antidiabetics. Based on the initial review, they were registered at the Family Physician-led GOPC or referred to the diabetologist (see Figure 1 for participants' flow during the study).

\section{Duration of the study}

The study was conducted over a period of 4 weeks.

\section{Data analysis}

Data were analysed using the Statistical Package for Social Sciences (SPSS) version 22.0. The respondents' characteristics (socio-demographic and clinical) were described using appropriate tables and charts. Continuous variables were summarised as mean and standard deviations, whilst categorical variables were summarised as percentages. The prevalence of missed prediabetes diagnosis was calculated. The proportion of respondents who missed the opportunity for prediabetes screening based on each risk factor was calculated. In addition, the proportion of respondents with multiple missed opportunities was also calculated. The proportions of missed prediabetes diagnoses based on the major criteria for screening and the number of risk factors were estimated.

\section{Ethical considerations}

Ethical approval to conduct the study was obtained from the Research Ethics Committee of Federal Medical Centre Abeokuta, with protocol number FMCA/470/ HREC/10/2016/30 and Federal Wide Assurance Number U.S./REG. NO.: FWA/00018660/02/28/2017. Informed consent was obtained from all the participants. A sample of the consent form is presented in Appendix 2.

\section{Results}

Of the 427 respondents who were eligible and interviewed for the study, 10 were lost to follow-up and had missing data. Data analysis was performed for 417 respondents, which gave a completion rate of $97.7 \%$.

The mean age of the respondents was $43.74 \pm 16.32$ years and $59.2 \%$ of them were women (Table 1 and 2 ).

The incidences of missed prediabetes and diabetes diagnoses amongst the respondents were $8.8 \%$ and $1.0 \%$, respectively (Figure 2).

The prevalence of missed opportunities for the prediabetes and diabetes risk factors ranged from $2.2 \%$ to $44.1 \%$ (Table 3 ).

Amongst the respondents, $79.9 \%$ had at least one guidelinerecommended risk factor for screening but were missed by the doctors (Table 4). The proportions of respondents who were missed based on the two major criteria recommended by $\mathrm{ADA}$ were $44.1 \%$ for age $\geq 45$ years and $17 \%$ for age $<45$ years with $\mathrm{BMI} \geq 25 \mathrm{~kg} / \mathrm{m}^{2}$ (Table 5 ). 


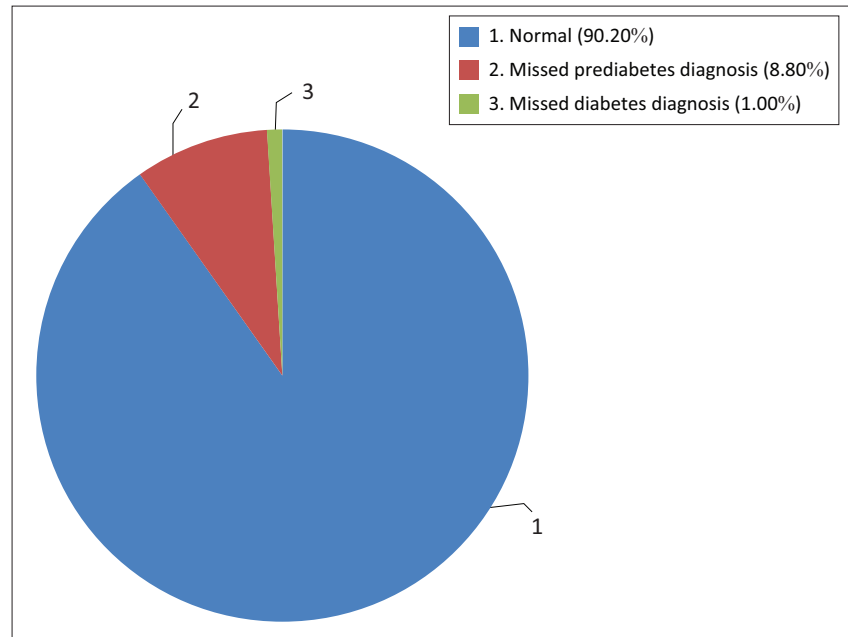

FIGURE 2: Incidences of missed prediabetes and diabetes diagnoses amongst respondents.

\begin{tabular}{|c|c|c|c|}
\hline \multirow[t]{2}{*}{ Variable } & \multirow[t]{2}{*}{ Categories } & \multicolumn{2}{|c|}{ Frequency } \\
\hline & & $n$ & $\%$ \\
\hline \multirow[t]{4}{*}{ Age } & $<45$ years & 233 & 55.9 \\
\hline & $45-54$ years & 68 & 16.3 \\
\hline & $55-64$ years & 55 & 13.2 \\
\hline & $\geq 65$ years & 61 & 14.6 \\
\hline \multirow[t]{2}{*}{ Gender } & Male & 170 & 40.8 \\
\hline & Female & 247 & 59.2 \\
\hline \multirow[t]{2}{*}{ Marital status } & Single & 89 & 21.3 \\
\hline & $\begin{array}{l}\text { Married } \\
\text { (current or previous) }\end{array}$ & 328 & 78.7 \\
\hline \multirow[t]{3}{*}{ Religion } & Christian & 278 & 66.7 \\
\hline & Islam & 136 & 32.6 \\
\hline & Traditional & 3 & 0.7 \\
\hline \multirow[t]{4}{*}{ Ethnicity } & Yoruba & 382 & 91.6 \\
\hline & Hausa & 3 & 0.7 \\
\hline & Igbo & 18 & 4.3 \\
\hline & Others & 14 & 3.4 \\
\hline \multirow[t]{4}{*}{ Level of education } & No formal education & 38 & 9.1 \\
\hline & Primary & 76 & 18.2 \\
\hline & Secondary & 115 & 27.6 \\
\hline & Tertiary & 188 & 45.1 \\
\hline
\end{tabular}

TABLE 2: Summary statistics of the continuous variables.

\begin{tabular}{lccc}
\hline Variable & Minimum & Maximum & $\begin{array}{c}\text { Mean } \pm \text { standard } \\
\text { deviation }\end{array}$ \\
\hline Age (years) & 18 & 90 & $43.74 \pm 16.32$ \\
BMI $\left(\mathrm{kg} / \mathrm{m}^{2}\right)$ & 14.47 & 42.51 & $24.00 \pm 4.88$ \\
SBP $(\mathrm{mmHg})$ & 80 & 220 & $117.94 \pm 19.02$ \\
Diastolic blood pressure $(\mathrm{mmHg})$ & 50 & 120 & $73.45 \pm 12.68$ \\
Waist circumference $(\mathrm{cm})$ & & & \\
All participants & 57 & 136 & $89.17 \pm 12.29$ \\
Male & & & $87.85 \pm 12.46$ \\
Female & & & $90.07 \pm 12.11$ \\
FBG (mmol/L) & 4.00 & 11.61 & $4.94 \pm 0.68$ \\
\hline
\end{tabular}

BMI, body mass index; SBP, systolic blood pressure; FBG, fasting blood glucose.

The proportion of missed prediabetes and diabetes diagnosis was higher in respondents with the major criteria (age $\geq 45$ years and age $<45$ years with $\mathrm{BMI} \geq 25 \mathrm{~kg} / \mathrm{m}^{2}$ ) when compared with their opposite (age $<45$ years and respondents who do not belong to age $<45$ years with $\mathrm{BMI} \geq 25 \mathrm{~kg} / \mathrm{m}^{2}$ ) (Figure 3). The higher the number of risk
TABLE 3: Magnitude of missed opportunity based on the guidelinerecommended risk factors for prediabetes screening.

\begin{tabular}{lcc}
\hline Variable & $\boldsymbol{n}$ & $\boldsymbol{\%}$ \\
\hline Age & 233 & 55.9 \\
$<45$ years & 184 & 44.1 \\
$\geq 45$ years & & \\
Family history of diabetes & 174 & 41.7 \\
Yes & 243 & 58.3 \\
No & & \\
Previous history of gestational diabetes & 9 & $\mathbf{2 . 2}$ \\
Yes & 198 & 47.5 \\
No & 210 & 50.3 \\
Not applicable & & \\
Previous history of big baby & 41 & 9.9 \\
Yes & 167 & 40.0 \\
No & 209 & 50.1 \\
Not applicable & & \\
BMI & 269 & 64.5 \\
$<25 \mathrm{~kg} / \mathrm{m}^{2}$ & $\mathbf{9 8}$ & $\mathbf{2 3 . 5}$ \\
$\mathbf{2 5 - 3 0} \mathrm{kg} / \mathrm{m}^{2}$ & $\mathbf{5 0}$ & $\mathbf{1 2 . 0}$ \\
$\geq \mathbf{3 0} \mathrm{kg} / \mathrm{m}^{2}$ & & \\
Waist circumference & $\mathbf{8 5}$ & 66.4 \\
Normal & 277 & $\mathbf{3 3 . 6}$ \\
Abnormal & $\mathbf{1 4 0}$ & $\mathbf{2 0 . 4}$ \\
Hypertension & & \\
No & 332 & \\
Yes & & \\
\hline
\end{tabular}

Note: The data set in bold indicates the respondents who had the various guidelinerecommended risk factors for prediabetes

BMI, body mass index.

TABLE 4: Proportion of missed opportunities based on number of guidelinerecommended specific risk factors for screening.

\begin{tabular}{lcc}
\hline Variable & \multicolumn{2}{c}{ Frequency } \\
\cline { 2 - 3 } & $\boldsymbol{n}$ & $\mathbf{\%}$ \\
\hline No risk factor & 84 & 20.1 \\
One risk factor & 109 & 26.1 \\
Two risk factors & 83 & 19.9 \\
Three risk factors & 82 & 19.7 \\
Four risk factors & 38 & 9.1 \\
Five risk factors & 15 & 3.6 \\
Six risk factors & 6 & 1.5 \\
Seven risk factors & 0 & 0.0 \\
At least one risk factor & 333 & 79.9 \\
No risk factor & 84 & 20.1 \\
\hline
\end{tabular}

TABLE 5: Magnitude of missed opportunity based on the guideline-recommended major criteria for prediabetes screening.

\begin{tabular}{lccc}
\hline Variable & Category & \multicolumn{2}{c}{ Frequency } \\
\cline { 3 - 4 } & & $\boldsymbol{n}$ & $\mathbf{\%}$ \\
\hline Age $\geq 45$ years & Yes & 184 & 44.1 \\
& No & 233 & 55.9 \\
Age $<45$ years with $\mathrm{BMI} \geq 25 \mathrm{~kg} / \mathrm{m}^{2}$ & Yes & 71 & 17.0 \\
& No & 346 & 83.0 \\
Age $>45$ years and/or BMI $\geq 25 \mathrm{~kg} / \mathrm{m}^{2}$ & Yes & 254 & 60.9 \\
& No & 163 & 39.1 \\
\hline
\end{tabular}

BMI, body mass index

factors present in the respondents, the higher the proportion of respondents with prediabetes and diabetes (Figure 4).

\section{Discussion}

To the authors' knowledge, studies that have examined the magnitude of missed opportunities for blood glucose screening in routine primary care physicians' visits are non-existent 


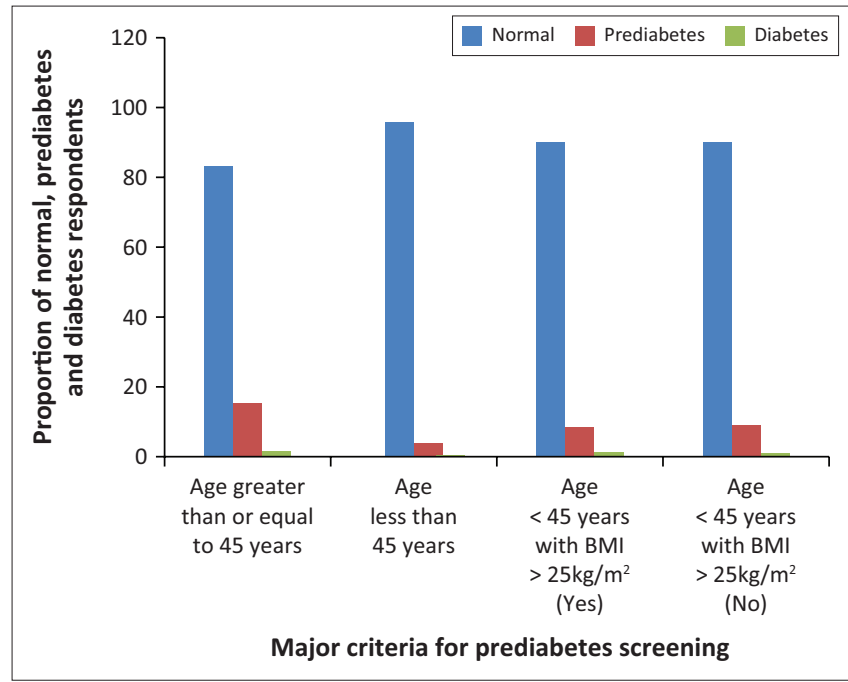

FIGURE 3: Proportion of missed prediabetes and diabetes diagnosis based on the major criteria.

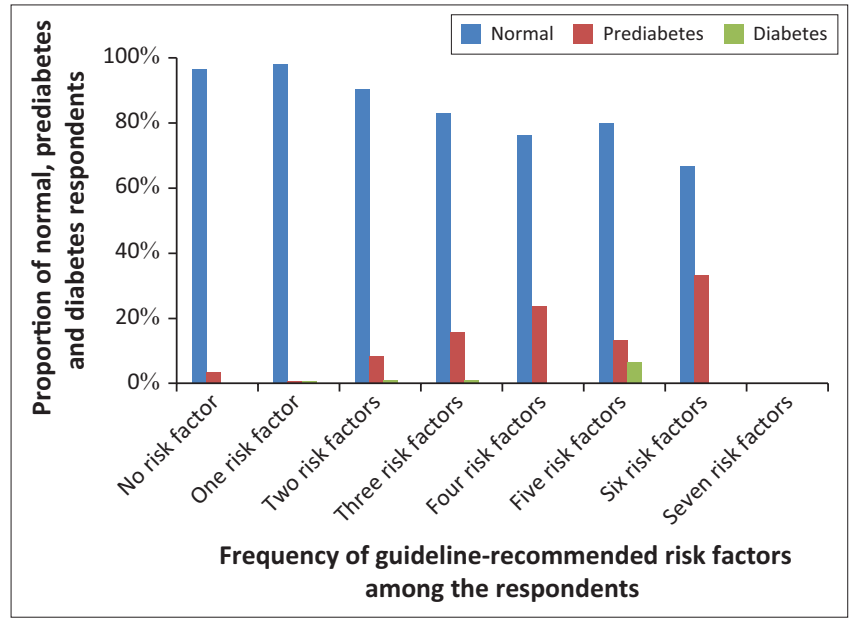

FIGURE 4: Proportion of prediabetes and diabetes based on the number of guideline-specific risk factors.

in Africa. The majority of the studies on prediabetes have centred on the burden of prediabetes in primary care and primary care physicians' practice vis-à-vis diabetes evaluation and management. ${ }^{1,2,3,4,5,6,7,8}$ This study is, therefore, addressing an important gap in the literature.

The proportion of respondents with prediabetes who would have been missed by primary care physicians in this study was approximately $9 \%$. Prediabetes in primary care is often unrecognised, with a consequent loss of opportunities for diabetes prevention. Whilst few studies have been conducted on this topic in developed countries, ${ }^{19,22,29,30}$ there is a paucity of studies on the magnitude of missed prediabetes diagnosis amongst primary care patients in Nigeria.

The general consensus of the few studies conducted on this topic is that primary care physicians still under-screen primary care patients for prediabetes and other chronic diseases..$^{19,22,29,30}$ A study was conducted by Rieger et al. ${ }^{19}$ in the United States of America amongst 80 non-diabetic adult patients who were already flagged in the electronic medical record (EMR) for blood glucose screening because their BMI was greater than $25 \mathrm{~kg} / \mathrm{m}^{2}$. This was done to improve screening for prediabetes by doctors. Despite EMR flagging, only $17(21 \%)$ of the patients were screened by the doctors. ${ }^{19}$ Similarly, Bauer conducted a study on the predictors of missed opportunities for blood glucose screening amongst 274 church-affiliated African-Americans and found that, based on self-report, the proportion of those who were screened in the past one year was $54 \%{ }^{29}$

Based on the ADA protocol, which states that asymptomatic adults aged $\geq 45$ years or $<45$ years who have BMI $\geq 25 \mathrm{~kg} / \mathrm{m}^{2}$ with additional risk factors should undergo prediabetes screening, ${ }^{10}$ this study showed that $44.1 \%$ and $17.0 \%$ of the respondents, respectively, met the criteria but missed the opportunities to be screened. Interestingly, amongst the respondents in this study who had prediabetes and/or diabetes, $75 \%$ of them were aged 45 years and over. It is also noteworthy that the primary care physicians in this study even failed to screen respondents who had four or more risk factors. Remarkably, the incidence of prediabetes in respondents with $\geq 4$ risk factors was over $10 \%$.

The lack of screening and detection exemplified in this study should be considered in light of the fact that most of these respondents have other cardiovascular risk factors, more importantly, hypertension (incidence of $20.4 \%$ ), a common comorbid condition with diabetes. The poor cardiovascular outcome that is associated with co-existing dysglycaemia and hypertension underscores the importance of early detection at prediabetes stage to reverse the transition of prediabetes to diabetes.

Although our study did not investigate why primary care physicians do not often screen for prediabetes, potential explanations from the literature include poor knowledge about various published prediabetes screening guidelines ${ }^{22,31}$ and a lack of awareness of the potential effect of interventions in reducing diabetes. ${ }^{29}$ For some physicians, screening for prediabetes in patients with many comorbidities may not be regarded as a priority. ${ }^{20,32}$ Beyond the physicians' inertia in screening patients, other barriers to screening include cost, transportation and mistrust of the healthcare system. ${ }^{29}$

The increased incidence of missed prediabetes diagnosis with age $\geq 45$ years observed in this study is in agreement with previous studies on this topic. $6,7,8,33,34$ Age $\geq 45$ years has been consistently shown to be associated with prediabetes and diabetes. ${ }^{6,7,8,33,34}$ Amongst the risk factors cited by various professional organisations for prediabetes and diabetes screening, ${ }^{9,10,11,12,13,14}$ the use of age as a screening tool will cost the physicians nothing in terms of time and energy. Despite its strong association with prediabetes and cost-effectiveness, it is still being used sparingly by primary care physicians. ${ }^{29}$ For example, $44.1 \%$ of respondents in this study met the criteria for screening (based on age), but these respondents were missed by the primary care physicians. An American study conducted by Bauer et al. also reported that $14 \%$ of respondents missed opportunities of being screened despite meeting the criteria for screening based on age. ${ }^{29}$ 
Over one-third (35.5\%) of the respondents in this study missed opportunities for prediabetes screening despite having BMI $\geq 25 \mathrm{~kg} / \mathrm{m}^{2}$. It must be pointed out that this study was conducted in a clinic where the clinic doctors had the opportunity to know the BMI because the weight and height of patients are routinely measured by the nurses as part of the vital signs before the patient sees a doctor. Based on the authors' anecdotal experience, the situation may be worse in a typical primary care clinic seen in Nigeria and other developing countries, where basic instruments for vital signs assessment may not be available. This is similar to the finding in an American study where an EMR had flagged patients with $\mathrm{BMI}>25 \mathrm{~kg} / \mathrm{m}^{2}$ prior to seeing a doctor yet still reported only $17(21 \%)$ of the 80 patients flagged as being screened for prediabetes. ${ }^{19}$ The higher proportion of missed prediabetes diagnoses in respondents with BMI $>25 \mathrm{~kg} / \mathrm{m}^{2}$, when compared with respondents with BMI $<25 \mathrm{~kg} / \mathrm{m}^{2}$ in this study, corroborated the findings of previous studies on this subject ${ }^{7,35}$ as well as various professional organisations' screening protocols, $, 10,11,12,13,14$ which support the screening based on BMI.

Systematic reviews and meta-analyses have shown that BMI and waist circumference measurement were useful in predicting diabetes. ${ }^{36,37}$ However, whilst there is a high sensitivity for the waist circumference that may be attributed to increase awareness of the disease in the public, the specificity in diagnostic criteria necessary for clinical practice is low. ${ }^{38}$ Therefore, most national organisations base their screening protocols on BMI and have not included the waist circumference measurement in their protocols. ${ }^{9,10,11,12,13,14}$

Primary care physicians may find the risk factors, in particular, age $\geq 45$ years and $\mathrm{BMI}>25 \mathrm{~kg} / \mathrm{m}^{2}$, to be a worthwhile starting point. The clinic nurses who measure vital signs can be helpful in this area by flagging any patient aged 45 years and above and/or BMI $>25 \mathrm{~kg} / \mathrm{m}^{2}$ during vital signs assessment. The primary care physician clinic can also be equipped with point of care testing for blood glucose. These approaches may improve the rate of blood glucose screening amongst high-risk primary care patients. Interventions to overcome previously identified barriers to prediabetes screening guideline adherence should be implemented, whilst further research should be conducted to identify other barriers and interventions in order to overcome them.

This study has some limitations. The paucity of research on this topic made it difficult for the authors to calculate the appropriate sample size. Nonetheless, the sample size used has highlighted the magnitude of missed opportunities for prediabetes screening in resource-poor primary care settings. Whilst FBG is equally appropriate in screening for prediabetes,$^{10}$ it would have been more appropriate if the oral glucose tolerance test, which is the gold standard, had been used. The use of capillary blood glucose may also be a limitation. However, it has been shown that photometric venous and glucometric capillary glucose estimations compare well with each other. ${ }^{39}$ The setting of the study at a GOPC at a tertiary hospital is not a typical primary healthcare setting. The practice of primary healthcare at this clinic cannot escape possible tertiary care influence. This could, therefore, have impacted the study findings. Other factors that could affect the blood pressure, for example, smoking, recent consumption of coffee and so on, may have had an impact on the blood pressure values obtained in this study.

\section{Conclusion}

This study revealed that there are indeed missed opportunities for prediabetes screening in primary care. The finding that high-risk patients with prediabetes in our setting often missed opportunities to be identified through screening suggests that primary care physicians in our setting need to improve on the practice of prediabetes screening. There is a need to conduct similar studies in other primary healthcare settings in order to assess whether there is consistency in the findings.

\section{Acknowledgements}

The authors appreciate the contributions of their colleagues in the Department of Family Medicine, Federal Medical Centre, Abeokuta.

\section{Competing interests}

The authors declare that they have no financial or personal relationships that may have inappropriately influenced them in writing this article.

\section{Authors' contributions}

All authors contributed equally to this work.

\section{Funding information}

No external funding was received for this study. Financing of the project was exclusively at the expense of the researchers.

\section{Data availability statement}

Data sharing is not applicable to this article as no new data were created or analysed in this study.

\section{Disclaimer}

The views and opinions expressed in this article are those of the authors and do not necessarily reflect the official policy or position of any affiliated agency of the authors.

\section{References}

1. Bullard KM, Saydah SH, Imperatore G, et al. Secular changes in U.S. prediabetes prevalence defined by hemoglobin A1c and fasting plasma glucose: National Health and Nutrition Examination Surveys, 1999-2010. Diabetes Care 2013;36(8):2286-2293. https://doi.org/10.2337/dc12-2563

2. Mainous AG, Tanner RJ, Baker R, Zayas CE, Harle CA. Prevalence of prediabetes in England from 2003 to 2011: Population-based, cross-sectional study. BMJ Open 2014;4:e005002. https://doi.org/10.1136/bmjopen-2014005002 
3. Khalil SHA, Abdelaziz SI, Al Shammary A, et al. Prediabetes management in the Middle East Africa and Russia: Current status and call for action. Diab Vasc Dis Res. 2019;16(3):213-226. https://doi.org/10.1177/1479164118819665

4. Rasaki SO, Kasali FO, Biliaminu SA, et al. Prevalence of diabetes and pre-diabetes in Oke-Ogun region of Oyo State, Nigeria. Cogent Med. 2017;4:1326211 https:// doi.org/10.1080/2331205X.2017.1326211

5. Oyegbade OO, Abioye-Kuteyi EA, Kolawole BA, Ezeoma IT, Bello IS. Screening for diabetes mellitus in a Nigerian family practice population. S Afr Fam Pract. 2007:8:15-15d. https://doi.org/10.1080/20786204.2007.10873612

6. Nwatu CB, Ofoegbu EN, Unachukwu CN, Young EE, Okafor Cl, Okoli CE. Prevalence of prediabetes and associated risk factors in a rural Nigerian community. Int J Diabetes Dev Ctries. 2016;36(2):197-203. https://doi.org/10.1007/s13410-015-0401-5

7. Ezeala-Adikaibe BA, Mbadiwe N, Okwara C, et al. Diabetes and pre-diabetes among adults in an urban slum in South East Nigeria. J Diab Mellitus. 2018;8:131-144. https://doi.org/10.4236/jdm.2018.84013

8. Gezawa ID, Puepet FH, Mubi BM, et al. Socio-demographic and anthropometric risk factors for type 2 diabetes in Maiduguri, North-Eastern Nigeria. Sahel Med J. 2015;18(1):S1-S7. https://doi.org/10.4103/1118-8561.149495

9. World Health Organization. Definition, diagnosis and classification of diabetes mellitus and its complications: Report of a WHO consultation. Part 1, Diagnosis and classification of diabetes mellitus [homepage on the Internet]. World Health Organization; 1999 [cited 2003 Dec 12]. Available from: https://apps.who. int/iris/handle/10665/66040

10. American Diabetes Association. Classification and diagnosis of diabetes: Standards of medical care in diabetes - 2019. Diabetes Care. 2019;42(1):S13-S28. of medical care in diabetes - 201
https://doi.org/10.2337/dc19-S002

11. AACE Diabetes Mellitus Clinical Practice Guidelines Task Force. American Association of Clinical Endocrinologists medical guidelines for clinical practice for Association of Clinical Endocrinologists medical guidelines for clinical practice for the management of diabetes melt
https://doi.org/10.4158/EP.13.S1.1

12. US Preventive Services Task Force. Screening for type 2 diabetes mellitus in adults: US Preventive Services Task Force recommendation statement. Ann Intern Med. 2008;148(11):846-854. https://doi.org/10.7326/0003-4819-148-11-2008060302008;1 0000

13. LaRocque $P$, Beard JM, Mintz $M$. Type 2 diabetes prevention and treatment. AAFP CME Bull. 2009;8(1):1-5.

14. American Congress of Obstetricians and Gynaecologists. Patient education pamphlet AP142: Diabetes and women [homepage on the Internet]. American Congress of Obstetricians and Gynaecologists. [cited 2011 Apr 19]. Available from: http://www.acog.org/publications/patienteducation/bp142cfm

15. Diabetes Prevention Program Research Group. The prevalence of retinopathy in impaired glucose tolerance and recent-onset diabetes in the Diabetes Prevention Program. Diabet Med. 2007;24:137-144. https://doi.org/10.1111/ j.1464-5491.2007.02043.x

16. Hing E, Uddin S. Visits to primary care delivery sites: United States, 2008. NCHS Data Brief. 2010;(47):1-8. https://doi.org/10.1037/e665592010-001

17. Willens $D$, Cripps $R$, Wilson $A$, Wolff $K$, Rothman R. Interdisciplinary team care for diabetic patients by primary care physicians, advanced practice nurses, and clinica pharmacists. Clin Diab. 2011;29:60-68. https://doi.org/10.2337/diaclin.29.2.60

18. Tomasik T, Windak A, Seifert B, Kersnik J, Jozwiak J. Treatment targets in patients with type 2 diabetes set by primary care physicians from Central and Eastern Europe. Eur

19. Rieger $C$. Pre diabetes screening in primary care. Doctor of nursing practice final manuscripts [homepage on the Internet]. San Diego, CA: Digital USD, 2016 [cited 2016 May 21]; p. 29. Available from: https://digital.sandiego.edu/dnp/29

20. Mainous AG, Tanner RJ, Baker R. Prediabetes diagnosis and treatment in primary care. J Am Board Fam Med. 2016;29(2):283-285. https://doi.org/10.3122/ jabfm.2016.02.150252

21. Jingi AM, Nansseu JR, Noubiap JJ. Primary care physicians' practice regarding diabetes mellitus diagnosis, evaluation and management in the West region of Cameroon. BMC Endocr Disord. 2015;15:18. https://doi.org/10.1186/s12902 015-0016-3
22. Nansseu JRN. Primary care physicians and diabetes mellitus care in sub-Saharan Africa: Still very far behind the goals. Prim Health Care. 2015;5(3):208-209. https://doi.org/10.4172/2167-1079.1000208

23. World Health Organization-Nigeria. [homepage on the Internet]. [cited 2018 May 17]. Available from: https://www.who.int/workforcealliance/countries/nga/ en/_en

24. Araoye MO. Subject selection: Sample size determination. In: Araoye MO, editor. Research methodology with statistics for health and social sciences. 1st ed. Ilorin: Nathadex; 2003. p. 117-118.

25. Pickering TG, Hall JE, Appel LJ, et al. Recommendations for blood pressure measurement in humans and experimental animals part 1: Blood pressure measurement in humans. A statement for professionals from the subcommitte of professional and public education of the American Heart Council on High Blood of professional and public education of the American Heart Council on High Blood HYP.0000150859.47929.8e

26. Aram VC, George LB, Henry R, William CC. The seventh report of the Joint National Committee on prevention, detection, evaluation, and treatment of high blood pressure: The JNC 7 report. JAMA. 2003;289:2560-2572. https://doi.org/10.1001/ jama.289.19.2560

27. World Health Organization. The international classification of adult underweight, overweight and obesity according to BMI. Geneva: WHO; 2004.

28. World Health Organization. Waist circumference and waist-hip ratio: Report of a WHO expert consultation. Geneva: World Health Organization (WHO); 2008.

29. Bauer AG, Berkley-Patton J, Thompson CB, Christensen K. Predictors and missed opportunities for blood glucose screening among African Americans: Implications for church-based populations. J Health Dispar Res Pract [serial online] 2019;12(2):72-87. [cited 2019 Mar 12]. Available from: http://digital.sandiego. edu/dnp/29

30. Tirpan K, Topuzoglu A, Topuzoglu AB. Missed chronic disease prevention opportunities in primary health care clinics in Turkey. Nobel Medicus. 2009;5(3):33-39.

31. Tseng E, Greer RC, O'Rourke P, et al. Survey of primary care providers' knowledge of screening for, diagnosing and managing prediabetes. J Gen Intern Med. 2017;32(11):1172-1178. https://doi.org/10.1007/s11606-017-4103-1

32. Kandula NR, Moran MR, Tang JW, O'Brien MJ. Preventing diabetes in primary care: Providers' perspectives about diagnosing and treating prediabetes. Clin Diab J. 2018;36(1):59-66. https://doi.org/10.2337/cd17-0049

33. Enrique LUB, Héctor RMR, José RTS, Aurora HH, Laura CS, Alfonso MCM Prevalence of pre-diabetes in young Mexican adults in primary health care. Fam Pract. 2014;0(0):1-6.

34. Muthunarayanan L, Ramraj B, Russel JK. Prevalence of prediabetes and its associated risk factors among rural adults in Tamil Nadu. Arch Med Health Sci 2015;3:178-184. https://doi.org/10.4103/2321-4848.171899

35. Iloh GUP, Uchenna NR, Obiegbu NP. Risk factors of pre-diabetes among adult Nigerians with essential hypertension in a resource-constrained setting of a primary care clinic in Eastern Nigeria. Am J Health Res. 2013;1(3):56-64. https://doi.org/10.11648/j.ajhr.20130103.14

36. Vazquez G, Duval S, Jacobs D, Silventoinen K. Comparison of body mass index, waist circumference, and waist/hip ratio in predicting incident diabetes: A metaanalysis. Epidemiol Rev. 2007;29:115-128. https://doi.org/10.1093/epirev/ mxm008

37. Qiao $Q$, Nyamdorj R. Is the association of type II diabetes with waist circumference or waist-to-hip ratio stronger than that with body mass index? Eur J Clin Nutr. 2010;64:30-34. https://doi.org/10.1038/ejcn.2009.93

38. World Health Organization. Waist circumference and waist-hip ratio: Report of a WHO expert consultation [homepage on the Internet]. 2008. [cited 2018 Dec 12] Available from: http://citeseerx.ist.psu.edu/viewdoc/download?doi=10.1.1.418.3 02\&rep=rep1\&type $=$ pdf

39. Adnana M, Imamb F, Shabbira I, Alia Z, Rahata R. Correlation between capillary and venous blood glucose levels in diabetic patients. Asian Biomed. 2015;9(1):55-59. https://doi.org/10.5372/1905-7415.0901.368 


\section{Appendix 1: Questionnaire}

RESEARCH PROFORMA ON MAGNITUDE OF MISSED OPPORTUNITIES FOR PREDIABETES SCREENING AMONGST NON-DIABETIC ADULTS ATTENDING THE FAMILY PRACTICE CLINIC OF A TERTIARY HOSPITAL IN WESTERN NIGERIA - IMPLICATION FOR DIABETES PREVENTION

Hospital research ethics committee assigned number:

Protocol number:

Good day Sir/Madam,

Thank you for consenting to participate in this study. This research is about evaluation of the magnitude of missed opportunities for prediabetes screening amongst Nigerian primary care patients and its implications on prevention of diabetes. It will help us serve you better. Your cooperation is needed to truthfully answer the questions below. All information will be strictly confidential and it will take only a few minutes. Thank you.

Serial number.

Hospital number

Date

\section{A SOCIO-DEMOGRAPHIC VARIABLES}

1) Age

2) Gender:

.............. years

$\begin{array}{ll}\text { (i) Male } & \text { (ii) Female }\end{array}$

3) Marital status:

4) Religion:

(i) Single (ii) Married

(iii) Divorced

(i) Islam

5) Ethnic group:

(i) Yoruba

(ii) Christianity

(iii) Traditional Belief

(iii) Igbo

(i) No formal education

(iv) Tertiary
(iv) Separated
(v) Widowed
(iv) Others
(iv) Others
(ii) Primary
(iii) Secondary

7) What do you do for a living?

8) What is your average monthly earning

\section{B CLINICAL FACTORS}

9) Do your family members (parent or sibling) have diabetes? $\quad \square$ Yes $\quad \square$ No

10) Have you ever been found to have high blood sugar during pregnancy? $\square$ Yes $\square$ No

11) Have you ever given birth to a large baby weighing $4.1 \mathrm{~kg}$ or more? $\square$ Yes $\square$ No

\section{ANTHROPOMETRIC MEASUREMENT}
12) Weight
13) Height
14) BMI
15) Waist circumference
16) Systolic blood pressure
17) Diastolic blood pressure

\section{INVESTIGATION}

18) Fasting blood glucose 


\section{Appendix 2: Informed consent}

Dear Sir/Madam,

I hereby seek your consent to participate in this research.

I am a doctor at the Department of Family Medicine, Federal Medical Centre, Abeokuta. I intend to evaluate the magnitude of missed opportunities for prediabetes screening amongst Nigerian primary care patients and its implications on prevention of diabetes. This may assist in improving the rate of prediabetes detection and diabetes prevention interventions.

If you consent, a questionnaire will be administered on you followed by a physical examination and blood tests. The procedure will last for about 20 min. The result of this project will be published in a journal.

Your participation is entirely of your own free will and you can withdraw from the study at any time you like without explanation. Refusal to participate in the study will not affect your treatment in any way. You have the right to refuse to answer any question you do not want to answer.

Please note that any information collected will remain confidential. Your name will not be attached to any published results. Kindly indicate your decision by signing in the space below.

Thank you.

Date and signature or thumbprint

of participant
Date and signature or thumbprint

of witness 